\title{
Responding to religious patients: why physicians have no business doing theology
}

\author{
Jake Greenblum, ${ }^{1}$ Ryan K Hubbard (i) ${ }^{2}$
}

${ }^{1}$ University Health System, San Antonio, Texas, USA

${ }^{2}$ Philosophy, Gulf Coast State College, Panama City, Florida, USA

\section{Correspondence to}

Dr Ryan K Hubbard, Social Sciences, Gulf Coast State College, Panama City 324011041, USA;

rhubbard2@gulfcoast.edu

Received 13 March 2019 Revised 16 April 2019 Accepted 7 May 2019

Published Online First 20 June 2019

\section{SLinked}

- http://dx.doi.org/10.1136/ medethics-2019-105790

- http://dx.doi.org/10.1136/ medethics-2019-105779

- http://dx.doi.org/10.1136/

medethics-2019-105756

- http://dx.doi.org/10.1136/

medethics-2019-105705

- http://dx.doi.org/10.1136/ medethics-2019-105703

- http://dx.doi.org/10.1136/ medethics-2019-105678

- http://dx.doi.org/10.1136/ medethics-2019-105818

Check for updates

(c) Author(s) (or their employer(s)) 2019. No commercial re-use. See rights and permissions. Published by BMJ.

To cite: Greenblum J, Hubbard RK. J Med Ethics 2019;45:705-710.

\section{ABSTRACT}

A survey of the recent literature suggests that physicians should engage religious patients on religious grounds when the patient cites religious considerations for a medical decision. We offer two arguments that physicians ought to avoid engaging patients in this manner. The first is the Public Reason Argument. We explain why physicians are relevantly akin to public officials. This suggests that it is not the physician's proper role to engage in religious deliberation. This is because the public character of a physician's role binds him/her to public reason, which precludes the use of religious considerations. The second argument is the Fiduciary Argument. We show that the patientphysician relationship is a fiduciary relationship, which suggests that the patient has the clinical expectation that physicians limit themselves to medical considerations. Since engaging in religious deliberations lies outside this set of considerations, such engagement undermines trust and therefore damages the patient-physician relationship

\section{INTRODUCTION}

A survey of the recent literature suggests that physicians are permitted to engage religious patients on religious grounds when the patient cites religious considerations for a medical decision. ${ }^{\text {ii }}$ in this paper, we argue that physicians ought to avoid citing religious considerations when helping the patient or surrogate come to a medical decision. ${ }^{\text {iii }}$ We begin by summarising what we call the dominant view. According to this view, physicians should engage with patients on the patient's or physician's own substantive religious grounds if the patient cites religious considerations during the process of deliberation. ${ }^{\text {iv }}$ We then offer two arguments against the dominate view. We call the first argument, the Public Reason Argument. Here, we explain why physicians are relevantly akin to public officials. This suggests that it is not the physician's proper

${ }^{\mathrm{i}}$ We mean physicians and other members of the medical team, such as nurses, as well as non-medical professionals, such as clinical ethicists and ethics committee members. For brevity's sake, we simply refer to physicians here. Importantly though we do not mean chaplains or other members of pastoral care, something we discuss more in depth later in the paper.

${ }^{i i}$ See especially Clarke ${ }^{11}$ Savulescu and Clark, ${ }^{6}$ Brett and Jersild, ${ }^{5}$ Conners and Smith ${ }^{4}$ and Orr and Genesen. ${ }^{2}$

${ }^{i i i}$ As we mention later, we do not think this duty is absolute. We do think it generally holds, except for in extraordinary circumstances.

${ }^{\text {iv }}$ For a taxonomy of different uses of miracle language, see Bibler. ${ }^{12}$ role to engage in religious deliberation. This is because the public character of a physician's role binds her to public reason, which precludes the use of religious considerations. We call the second argument the Fiduciary Argument. Here, we show that the patient-physician relationship is a fiduciary relationship, which suggests that the patient has the clinical expectation that physicians limit themselves to medical considerations. We argue that since engaging in religious deliberations lies outside this set of considerations, such engagement undermines trust and therefore damages the fiduciary relationship between patient and physician.

Two clarifications are in order before proceeding. The first is that our thesis does not entail that it is impermissible for physicians to pray with patients, since prayer itself is typically not given as a reason for or against a medical decision, and we are only interested in the medical decision-making process.

The second is that when patients use religious language, they may not in fact be appealing to actual religious considerations. Consider miracle language, for example. Sometimes when patients or their surrogates employ miracle language- 'We know a miracle will occur' in response to the physician's suggestion to move a patient to comfort care-they are simply 'expressing hope or optimism about the possibility of recovery'. ${ }^{1}$ Alternatively, patients might be expressing their anger or disappointment, possibly even using miracle language as a 'method to control the care team or even strike back at them'. For example, a family may deploy miracle language as a kind of trump card in an effort to punish the medical team for suggesting comfort measures. Our paper does not address responding to these kinds of implicit claims, and we fully acknowledge that it can be entirely appropriate for physicians to clarify what patients and their surrogates might mean when they employ religious language. We therefore assume that physicians are responding to religious reasons proper, such as the notion that God will supernaturally intervene to save a loved one.

\section{RELIGIOUS LANGUAGE PROPONENTS}

Those who support religious engagement make a variety of specific recommendations that can roughly be placed into three groups: the metaphysical response, the direct normative response and the alternative response. Below is a representative sampling of the responses from each of these groups.

First, the metaphysical response, which, for our purposes, concerns the nature of God's existence or miracles. Consider the parents of a son with brain cancer who are waiting for a miracle to cure him 
despite the fact that their son is unresponsive after 3 weeks of aggressive treatment. Orr and Genesen suggest saying to the parents that

Belief in God's ability to perform a miracle does not, however, imply that God will perform a miracle in a particular case. Experience tells us that miracles are rare occurrences....If God is sovereign and omnipotent, human choice or action is not needed to achieve God's goals. ${ }^{2}$ v

\section{Likewise, Clarke recommends noting that}

God is not restricted to miraculously healing only those children who are in intensive care. It is possible that God may intervene and initiate a miraculous cure after treatment is withdrawn. It is even possible that God will decide to bring a child back to live after it has died. ${ }^{3}$

\section{Similarly, DeLisser, argues that}

the physician can offer the thought that the miracle...may have already occurred, or may occur in some other way. For example, bitterly estranged family members are brought together because of the patient's illness... and to everyone's astonishment, they are able to reconcile. ${ }^{1}$

Finally, Connors and Smith maintain that the common understanding of miracles as natural law suspending events 'needs to be widened, moving from an exclusive fixation on categories of bodiliness and physical cure, to categories of acceptance and transformation'. 4 Again, what each of these responses has in common is that they concern metaphysical issues, namely, the nature of the divine and how it manifests itself.

Let us turn to the second kind of response, the direct normative response. This kind of response assumes that the patient's or surrogate's religious normative reason to prefer a particular course of action carries real normative weight. The direct normative response, however, maintains that the stated normative reason either does not apply in the manner the patient or surrogate assumes (ie, that it does not demand the particular action the person claims that it demands) or that it should be reinterpreted. In either case, this response engages with the patient on explicitly religious grounds.

One kind of direct normative response considers how to respond to those who believe that suffering is redemptive and demand continued treatment. Brett and Jersild recommend saying the following:

\section{Suffering may constitute a demanding school of self-development, but that truth hardly applies to (the believer's loved one)... The person who exalts suffering on Christian grounds distorts the Gospel by turning suffering into an end in itself. When all hope has been lost for the patient's recovery, the extension of suffering loses all meaning and becomes an inexcusable assault. ${ }^{5}$}

Clarke makes a similar move against Jehovah's Witnesses who refuse blood transfusions for their child. He says:

It is not specified in publicly available statements of the Jehovah's Witness doctrine that God will refuse to allow unwitting recipients of blood transfusions into heaven, and a child who has not freely chosen to have a blood transfusion has not committed a sin, from the Jehovah's Witness point of view. ${ }^{3}$

\footnotetext{
${ }^{\mathrm{v}}$ Sulmasy ${ }^{10}$ also makes this point.
}

These responses ask the patient or surrogate to rethink how a reason applies to a particular case. The former response implicitly agrees with the reason that suffering is spiritually redemptive but asks the patient or surrogate to apply this religious reason in a different way. The second response does not challenge the idea that there is a reason to refuse blood transfusions but asks the patient or surrogate to reconsider how this reason applies to children.

By contrast, consider a second kind of direct normative response. Take the example of those believers who seek continued treatment because, for them, such treatment is an expression of their 'faith to trust in God in the face of tragedy'. Brett and Jersild recommend the following reply:

Withholding aggressive life-sustaining measures...does not interfere with God's plan...it reflects the view that our mortality is built into God's creation, and that we accept this reality even under difficult circumstances. Accordingly, one is not compelled to continue every conceivable treatment while awaiting God's will to manifest itself. ${ }^{5}$

This kind of response does not ask the patient or surrogate to re-apply their reason.

Instead it is re-interpretative in nature, as it asks the patient or surrogate to re-interpret their understanding of faith to trust in God.

Similarly, consider those believers who think that God commands continued treatment because 'the life made possible by machinery is the life bestowed by God'. ${ }^{5}$ Brett and Jersild recommend replying that:

An alternative position is to draw a distinction between the life bestowed by God and the life maintained by a machine. Maintaining the latter kind of life is mandatory only if there is still a possibility of returning to the kind of human life bestowed by God-a life with some semblance of cognitive capacity and dignity....To sustain the life (of the believer's loved one) is to substitute the machine for God, or to make a god out of the machine. ${ }^{5}$

These representatives of the latter kind of direct normative response clearly prompt the physician to engage the patient or surrogate in a deep religious reflection about their stated normative reason. The physician, in essence, is charged with the task of asking the patient or surrogate to reflect on what their stated reason truly amounts to. What, to take just the previous quoted passage, does the stated religious reason of a 'life bestowed by God' really mean?

The alternative response is characterised by the alternative reasons it offers. It differs from the metaphysical response insofar as it does not refer to the nature of God's essential properties. The alternative response is, however, similar to the direct normative response insofar as it is normative in nature, yet the alternative response is distinct by offering competing reasons to think that God would prefer some action over another. In other words, in contrast to the direct normative response, which grants the religious believer's general normative position and offers an alternative interpretation of what that position entails, the alternative response simply offers a different reason to consider altogether.

One example of what we have in mind by the alternative response comes from Brett and Jersild, who suggest responding to miracle invocators by saying that the true test of faith is to place the patient's 'life in the hand of God'. 5 This kind of response does not deny the possibility of miracles (as, for instance, some versions of the metaphysical response do), nor does it offer a competing interpretation of a normative reason 
(as in the direct normative response), but instead it 'tempers the inclination to look for nature-defying events' by simply noting that there are other reasons to respond to the patient's situation in a different way. ${ }^{5}$

A final alternative response example is the following: imagine a Muslim father who wants his daughter to receive continued life support despite the fact that further treatment is unavailable. Orr and Genesen recommend responding with: 'God has commanded stewardship, expecting humans to use their bodies and resources wisely'. ${ }^{2}$

To summarise, the dominant view recommends that physicians engage with their patients on explicitly religious grounds in three categories of response: metaphysical, direct normative and alternative. In the next section, we contest this dominant view.

\section{ARGUMENTS AGAINST APPEALING TO RELIGIOUS CONSIDERATIONS}

In this section, we offer two arguments against physicians directly engaging in religious deliberation with patients in coming to medical decisions.

\section{The Public Reason Argument}

Public reasons are non-sectarian reasons. That is, public reasons are considerations that any reasonable person could recognise as counting in favour of something. Public reasons are crucially important for a free society, since free societies are fundamentally marked by moral pluralism, where members adhere to diverse religions and ethical outlooks. ${ }^{\text {vi }}$ Public reason as an ideal requires that public decisions be justified based on considerations that everyone-despite their differences in ethical outlookscould in principle accept as reasons. This helps ensure that the outcome of the decision shows proper respect to all its members.

The following example helps to illustrate why public decisions should be premised on only public reasons. Imagine a group of lawmakers who attempt to justify a policy which would regulate carbon emissions on vehicles. These lawmakers are of the Christian faith and attempt to justify this policy by claiming that the bible instructs us to not pollute the land. ${ }^{\text {vii }}$ By citing this reason, these lawmakers disrespect the public, Christian and non-Christian alike. They disrespect non-Christians insofar as they would obviously reject the ground of the decision. ${ }^{\text {viii }}$ But, importantly, they also disrespect their fellow Christians insofar as public officials in a morally pluralistic society have a duty to all citizens, not simply to those of other faith traditions, to cite only public reasons.

The Public Reason Argument maintains that the duty to avoid citing substantive religious reasons extends to physicians in their dealings with patients because physicians are relevantly akin to public employees. The following considerations support this claim: first, physicians accept government funds through Medicare or Medicaid. ${ }^{\text {ix }} 6$ Second, physicians make decisions that

\footnotetext{
${ }^{\text {vi }}$ See Rawls. ${ }^{13}$

vii See numbers 35:33-34 ESV, "You shall not pollute the land in which you live, for blood pollutes the land...You shall not defile the land in which you live, in the midst of which I dwell, for I the LORD dwell in the midst of the people of Israel".

${ }^{\text {viii }}$ A public reason that would justify carbon regulations is that clean air is necessary for the public's health.

${ }^{\mathrm{ix}}$ According to the Tax Policy Center, the federal government spent almost US\$1.1trillion in 2018. Medicare spent US $\$ 583$ billion, Medicaid and the Children's Health Insurance Programme spent US\$399 billion and the Department of Veterans
} Affairs spent US\$70 billion. See https://www.taxpolicycenter. affect the public allocation of medical resources. For example, the recommendation to keep a patient on life support may prevent another patient from using life support services when such services are scarce. ${ }^{5}$ Finally, physicians and medical institutions are regulated by the state through state medical boards. Because, then, physicians are akin to public employees, they ought to cite only public reasons in their capacity as professionals. ${ }^{x}$

We present the following case to further substantiate this argument.

Case 1

Mr. Kamala aged 51 years is a devout Hindu patient whose primary care physician refers him to an oncologist, Dr Chatterjee, after Mr. Kamala begins complaining of chest pain. While speaking to Mr. Kamala, Dr Chatterjee asks Mr. Kamala, a 20-year pack-aday smoker, about his medical history. Dr Chatterjee informs him that there is a new and medically promising lung cancer treatment available. She mentions this fact and then adds that since Lord Shiva urges us to purify our bodies, Mr. Kamala should take advantage of the treatment.

We suspect that most people would be taken aback in response to Dr Chatterjee. Indeed, most people would likely agree that the physician's religious claim is inappropriate, since it is not her place to offer religious considerations in the doctor's office. But what explains this agreement's intuitive appeal? A helpful way of articulating the claim that the physician is overstepping is that the 'place' or 'site' of the physician-which is partly constituted by her professional role as a physician-is public. It is not the physician's place to offer religious considerations because the site of her performing her professional role is a public one. This fact helps explain why it would be inappropriate for her to offer religious considerations and why the physician's role is public in nature. This explanation of our intuition regarding case 1 lends support to our claim that physicians-insofar as they are performing the role of a physician—ought to be bound by public reason. ${ }^{\mathrm{xi}}$

There is an important way in which this physician-patient interaction is private. Information regarding the patient's health, for example, should not be disclosed to the public. The conversation between the patient and physician is certainly private in this manner. So, this context is not public in the sense that information exchanged is public or is permitted to be public. Our argument, however, is drawing on a different sense of public. The site of the physician is public in the sense that her private conception of what constitutes a good life-as provided by her religion-should not explicitly influence or be brought into her professional deliberation with the patient. ${ }^{\text {xii }}$

org/briefing-book/how-much-does-federal-government-spendhealth-care According to the Centers for Medicare and Medicaid Services website, the federal government spent US\$694 billion in 2017 on physician and clinical services. See https://www.cms. gov/Research-Statistics-Data-and-Systems/Statistics-Trends-andReports/NationalHealthExpendData/downloads/highlights.pdf

${ }^{\mathrm{x}}$ See Greenblum and Kasperbauer ${ }^{14}$ for a discussion of considering physicians as akin to public officials.

${ }^{x i}$ It is important to note that the Public Reason Argument extends even to those physicians who are employed by religious hospitals, such as Catholic hospitals, which reportedly make up one in six hospital beds in the US. See https://www.aclu.org/news/ new-report-reveals-1-6-us-hospital-beds-are-catholic-facilitiesprohibit-essential-health-care.

${ }^{x i i}$ Thanks to an anonymous reviewer for asking us to elaborate on this issue. 
As an analogy, consider an instructor-student interaction at a public college. The exchange may be private in the sense that it would be inappropriate to publicise information to third parties. In the USA, for example, the Family Educational Rights and Privacy Act prohibits an instructor from revealing a student's grades to his or her parents unless the student gives written consent or is under 18. Nevertheless, the site of the exchange is public in the sense that it would be inappropriate for the instructor to give the student academic advice based on the instructor's religion. Like an instructor at a public college or university, the professional role of the physician is public in nature.

To close this section, one could raise the worry that a religious person may not consider our public reason standard to be neutral since it seems to prioritise secular-that is, scientific-reasons over other reasons. ${ }^{\text {xiii }}$ In response, we should clarify that we are prioritising public reasons and not all public reasons are scientific. There are many public reasons regarding ethical goodness or justice, for example, that are not scientifically based; rather, they are grounded in brute normative intuitions or shared social values. Furthermore, public reason does not necessarily conflict with religious considerations since the normative force of many, if not most, religious considerations can be captured by public reason. Finally, we should emphasise that we are not suggesting that religious considerations have no place in a hospital. We are suggesting that religious dialogue take place with the appropriate professionals, such as chaplains.

\section{The Fiduciary Argument}

We now turn to our second argument against appealing to religious considerations, the Fiduciary Argument. This argument begins by noting the obvious: the physician-patient relationship, like the attorney-client relationship and the guardian-ward relationship, is fiduciary. As such, one party entrusts the other with discretionary power over their practical interests and the trustee agrees to exercise that power. ${ }^{7 x i v}$ In the physician-patient relationship, the patient trusts the physician to use her expertise both to act in the patient's best interest and to do so in certain limited ways. ${ }^{\mathrm{xv}}$ For instance, the patient has the clinical expectation that when he enters a fiduciary relationship with a physician, the physician will make medical decisions based on considerations that are consistent with current medical science. Religious considerations such as miracles are not consistent with current medical science. So, just as it is troubling for the physician to consult the patient's horoscope in the joint medical decision-making process, it is also troubling for the physician to engage religious considerations. Referring to these kind of considerations lies beyond the scope of the physician's appropriate considerations and conveys the message that physicians are willing to flout the clinical expectations that partially constitute the patient-physician relationship. Citing religious reasons therefore impermissibly harms the patient-physician relationship by undermining trust. ${ }^{\text {xi }}$ To see this, consider case 2 .

\footnotetext{
xiii Thanks to an anonymous reviewer for raising this worry. ${ }^{x i v}$ See also the American Medical Association's opinion on the patient-physician relationship: https://www.ama-assn.org/ system/files/2019-01/code-of-medical-ethics-chapter-1_0.pdf.

${ }^{\mathrm{xv}}$ Our discussion of the fiduciary nature of the physician-patient relationship is consistent with Emanuel and Emanuel's preferred deliberative model of the physician-patient relationship as discussed in their piece 'Four Models of the Physician-Patient Relationship'. ${ }^{15}$

${ }^{x v i}$ We should note that this is an empirical claim and we have not found studies to support it. Nevertheless, we attempt to show that it's reasonable to accept.
}

Ms. Stevens is intubated and has been on the medical ICU for 10 days. Her attending physician, Dr Thompson, is contemplating whether to do a tracheostomy. Dr Thompson reaches out to Ms. Stevens' husband, her surrogate decision-maker, for his input. Mr. Stevens informs Dr Thompson that both he and his wife are Evangelical Christians and that, as such, they believe in miracles, the power of prayer, and therefore want Dr Thompson to 'do everything'. And, yet, despite Mr. Stevens' religious commitment, he states that he is extremely conflicted about whether Dr Thompson should actually perform the tracheostomy. Dr Thompson, a Christian herself and sensing that Mr. Stevens is leaning towards refusing the tracheostomy, which is medically indicated and also Dr Thompson's preferred choice, responds, "God is all powerful. His choices do not depend on individual prayers. Place your faith in His love, not in His willingness to answer your prayers". xvii

If a physician responds in the way Dr Thompson responds, he violates his fiduciary obligation.

One might think that the crucial worry with case 2 is not that the physician violates her fiduciary responsibilities, but that she manipulates the patient by citing a religious reason that she knows will have some persuasive effect. We disagree. The mere fact that the physician cites a reason that she knows will have persuasive effect is not evidence of manipulation, as, we are assuming, she genuinely believes in the reason's practical relevance. Moreover, even if, for the sake of argument, the physician does manipulate the patient by citing a religious reason that she knows will have persuasive effect, we think that what makes this kind of manipulation fundamentally morally troubling is her fiduciary role as a physician, not the mere fact of manipulation. ${ }^{\text {xviii }}$

Before turning to the next section, it is worth noting that the Public Reason Argument and the Fiduciary Argument are related, but logically distinct. They are related insofar as public reasons and the physician-patient relationship's fiduciary quality are practically intertwined. It makes sense, in other words, to say that physicians should only exercise their discretionary power by citing public reasons. Thus, it is difficult not to conclude that public reason is crucially relevant to the fiduciary relationship. Conversely, reasonable persons constrained by public reason in their public decision-making would clearly endorse the value of the physician-patient relationship's fiduciary quality. Nevertheless, the arguments are logically distinct: the Public Reason Argument hinges on the idea that physicians ought to be constrained by public reason, which grounds the claim against employing religious considerations. The Fiduciary Argument, by contrast, hinges on the claim that citing substantive religious considerations damages the fiduciary nature of the physician-patient relationship.

It is also worth noting that the Public Reason and Fiduciary Arguments have different scopes. The Public Reason Argument clearly only extends to liberal societies marked by moral pluralism, whereas the Fiduciary Argument extends to all societies. Two points are worth making here. First, as we pointed out in the previous paragraph, the two arguments are practically intertwined. Thus, even though the Public Reason Argument's theoretical scope is more limited, physicians in non-liberal societies seeking to exercise their discretionary power could practically do so by asking themselves whether the reasons they wish

\footnotetext{
xvii This is a version of one of Orr and Genesen's ${ }^{2}$ responses we mention earlier. We believe that we could substitute any of the responses we discussed in the first section of this paper for Case two and they would be equally troubling.

xviii We thank Jeanie Sauerland for raising this potential objection and discussing it with us.
} 
to cite are appropriately non-sectarian. Second, even though the Public Reason Argument's scope is more limited than the Fiduciary Argument, the Public Reason Argument is nevertheless crucial to explaining the strength of physicians' pro tanto duty to refrain from citing religious reasons. That is, we believe that the pro tanto duty is stronger, and thus more difficult to override, in liberal societies as compared with non-liberal societies, precisely because of the Public Reason Argument.

\section{OBJECTIONS}

In this section, we anticipate, and respond, to four potential objections to our view. The first objection is that implementing our view is simply not feasible. Because religion pervades the lives of some patients to such an extent that they are only able to deliberate in religious terms, physicians cannot always avoid appealing to religious considerations. Therefore, they cannot have a general obligation to avoid such appeals. As Janet Malek notes, 'Beliefs and values may...be difficult to separate from one's religious perspective...[F]or individuals who identify with a religious tradition, the process of thinking though ethical questions is likely to be intertwined with their religious worldview'.

In response, although it is certainly true that many people consider themselves to be highly religious, it is likely that a great majority of them can discuss matters in non-religious terms. We say this because virtually all persons in liberal democracies engage in the public sphere to some degree, especially considering the prevalence of social media and other venues of online communication. This suggests that most learn to discuss matters with people who do not share their religious convictions. It is likely that most persons can 'translate' their religious considerations into non-religious terms to be understood based on a set of values that all share, viz. in terms that are consistent with public reason. As Robert Audi puts it, 'A (religious) propertysuch as that of being commanded by God-can appear to human intelligence in more than one guise, say in a Kantian guise as the property of befitting the dignity of persons or in an agapistic guise as the property of being appropriate to loving treatment of others'. 'The sanctity of life', for example, has religious connotations and is often cited in Christian inspired arguments. However, this phrase can be translated as 'the intrinsic value of life', rendering the notion acceptable to public reason without losing any of the original notion's deliberative force. ${ }^{\text {xix }}$

The likelihood of 'translation' suggests that this first objection is less worrisome than it may initially appear since cases in which a patient is seemingly unable to discuss a treatment option based on public reason are likely few and far between. Nevertheless, this objection raises the important practical issue of what the physician should do-assuming our view is correct-in the few cases in which a patient cannot or is unwilling to discuss options on the basis of public reasons. In these rare cases, we believe the physician should request that a chaplain discuss matters with the patient. Serving as an intermediary, the chaplain can then represent the patient's view in a non-sectarian fashion to the physician.

The second objection is that not engaging religious patients on religious grounds is inconsistent with the 'kind of tolerance that ought to characterise a liberal polity'. ${ }^{10}$ This objection suggests that our view is intolerant to religious patients and disrespects

\footnotetext{
${ }^{x i x}$ This is not an endorsement of life's putative intrinsic worth. We simply mean to point out that 'life's intrinsic value' can be properly debated in the public sphere using tools like philosophy, as opposed to theology.
}

their right to live in accordance with their religion. It may be argued, for example, that not engaging with a patient's religious considerations fails to recognise the patient's autonomy and encourages adopting a patronising attitude towards those patients who are deemed too parochial to engage in rational deliberation.

To this important objection, we offer three responses. First, we think that non-engagement is respectful if it is motivated for the right reasons. For instance, if, as we have argued, one is motivated by the idea that public reason commands making public decisions based on non-sectarian reasons, then one's reasons are perfectly in keeping with the spirit of mutual respect that undergirds modern liberalism.

Second, if the animating concern behind this objection is that religious patients will feel disrespected as a result of non-engagement, then it is misguided. Recall that because most members of a liberal polity engage in a variety of public spheres, they will be able to cite public reasons and, therefore, are unlikely to feel this way. Furthermore, reasonable patients should not find their obligation to 'translate' their sectarian reasons into public reasons to be unduly burdensome, since they will recognise this duty to be constitutive of a free society marked by mutual toleration and respect. So although various persons may nevertheless feel disrespected by non-engagement, and although this is certainly bad, such feelings are not evidence of injustice.

Lastly, our view does not claim that religious patients' religious considerations should be ignored. As mentioned above, if a patient insists on deliberating on religious grounds, it is appropriate to seek the aid of a chaplain.

The third objection is that in many cases implementing our view would sacrifice better moral outcomes. For example, there may be cases in which a physician's refusal to engage in religious deliberation may cause the patient stress or alienation, which may be detrimental to their condition.

In response, and as we just pointed out, our view does not imply that patients' religious considerations should be ignored. We simply believe a division of labour is in order. Thus, our view adds value without any cost; the division of labour promotes public reason and the fiduciary relationship while simultaneously making room for religious considerations in their proper sphere. Moreover, our claim that physicians should refrain from engaging in religious deliberations is not absolute. In exceptional circumstances-say if refraining from substantive religious dialogue would cause the patient lethal stress-it may be permissible to override the duty to refrain from engaging religious considerations. If engaging in religious deliberation is the only feasible way to prevent a patient's death, then this consideration may outweigh the pro tanto obligation to not engage religious discourse. There may be non-lethal, overriding cases as well. For example, if the patient can only deliberate in religious terms, there is no chaplain available, and a decision must be made promptly, then it may be justified to engage in religious deliberation. Identifying overriding cases comes down to exercising wise judgement. Identifying the criteria for such cases is beyond the scope of this paper.

The fourth objection is that there may be cases in which, contrary to our view, a physician engaging with her patient on religious grounds may enhance or strengthen the physician-patient relationship. Particularly, if a patient deliberately seeks out a physician because he expects the physician to deliberate with him on religious grounds, then no expectation is breached when the physician offers religious considerations. So, as the objection goes, the trust between patient and physician is fully maintained. In these kinds of cases, the physician appealing to non-sectarian 
reasons would breach expectations, thereby harming the relationship.

In reply, we do not dispute that particular instances of substantive religious dialogue may promote physician-patient trust. Nevertheless, what generates the duty is not the potential for particular instances of physician-patient distrust. Rather, what generates the duty is that substantive religious dialogue will generally work towards undermining the physician-patient relationship. In other words, we are interested in the type of relationship promoted by refraining from substantive religious exchange, not specific instances where the particular relationship might be strengthened.

\section{CONCLUSION}

In this paper, we have argued that physicians have a moral duty to avoid engaging substantive religious considerations when helping patients or surrogates reach a medical decision. Our two arguments-the Political Reason and Fiduciary Argumentsestablish this conclusion. We believe, based on our limited experience but nevertheless numerous conversations with physicians about this topic, that most physicians would agree. It is therefore surprising that so much of the literature seems to encourage religious conversations between physicians and patients. We suspect that much of this literature is motivated by the idea that liberalism and modern medicine are fundamentally atheistic, and, so, at odds with religion. ${ }^{\mathrm{xx}}$ To the degree that this is so, we hope to have shown, especially via our Public Reason Argument, why this idea is mistaken. Physicians may or may not be personally religious, but, insofar as they are public officials, they have a pro tanto obligation to refrain from citing substantive religious reasons. This obligation clearly does not commit the physician to a belief in atheism nor does it preclude an appropriate role

\footnotetext{
${ }^{x x}$ For example, Orr and Genesen claim that 'Contemporary medicine has unfortunately adopted from the surrounding Western culture a post-modern attitude' which assumes that religious belief is 'mystical or irrational'. ${ }^{2}$ Also Polzer Casarez and Engebretson equate 'the totally secular side' of healthcare with 'imposing his (the physician's) views of religion (that of denial or atheism)' on the patient. ${ }^{16}$ Similarly, Bishop accuses liberalism of viewing traditional religious practices as blocking us 'from seeing the pure principles of ethics'. ${ }^{17}$
}

of spiritual care in medical contexts. So, neither liberalism nor modern medicine are in any way fundamentally opposed to religion. Those who maintain the contrary view appear to subscribe to a deeply flawed understanding of liberalism and its moral commitments.

Contributors RKH and JG contributed substantially and equally to the content, arguments and organisation of the paper.

Funding The authors have not declared a specific grant for this research from any funding agency in the public, commercial or not-for-profit sectors.

Competing interests None declared.

Patient consent for publication Not required.

Provenance and peer review Not commissioned; externally peer reviewed.

\section{ORCID iD}

Ryan K Hubbard http://orcid.org/0000-0003-2881-7138

\section{REFERENCES}

1 DeLisser HM. A practical approach to the family that expects a miracle. Chest 2009;135:1643-7.

2 Orr RD, Genesen LB. Requests for "inappropriate" treatment based on religious beliefs. J Med Ethics 1997:23:142-7.

3 Clarke S. When they believe in miracles. J Med Ethics 2013;39:582-3.

4 Connors RB, Smith ML. Religious insistence on medical treatment: Christian theology and re-imagination. Hastings Cent Rep 1996;26:23-30.

5 Brett AS, Jersild P. "Inappropriate" treatment near the end of life: conflict between religious convictions and clinical judgment. Arch Intern Med 2003;163:1645-9.

6 Savulescu, J. and Clarke, S.,. Waiting for a miracle. miracles, miraclism, and discrimination. South Med J 2007;100:1259-62.

7 Miller PB, Weijer C. Fiduciary obligation in clinical research. J Law Med Ethics 2006;34:424-40.

8 Malek J. The Appropriate Role of a Clinical Ethics Consultant's Religious Worldview in Consultative Work: Nearly None HEC Forum Sept, 2018:1-12.

9 Audi R, Wolterstorff N. Religion in the public square: The place of religious convictions in political debate. Rowman \& Littlefield, 1997.

10 Sulmasy DP. Distinguishing denial from authentic faith in miracles: a clinical-pastoral approach. South Med J 2007;100:1268-72.

11 Clarke S. Miracles, scarce resources, and fairness. Am J Bioeth 2018;18:65-6.

12 Bibler TM. Myrick C Shinall Jr \& Devan Stahl Responding to Those Who Hope for a Miracle: Practices for Clinical Bioethicists. AJOB 2018;18:40-51.

13 Rawls J. Political liberalism: Columbia University Press, 2005.

14 Greenblum J, Kasperbauer TJ. Forget evil: Autonomy, the physician-patient relationship, and the duty to refer. J Bioeth Inq 2018:15:313-7.

15 Emanuel EJ, Emanuel LL. Four models of the patient-physician relationship. JAMA 1992;267:2221-6.

16 Polzer Casarez RL, Engebretson JC. Ethical issues of incorporating spiritual care into clinical practice. J Clin Nurs 2012;21:2099-107.

17 Bishop JP. Modern liberalism, female circumcision, and the rationality of traditions. J Med Philos 2004;29:473-97. 